\title{
Features of Political News English in China Daily
}

\author{
Daan Fu \\ Foreign Languages Department, \\ North China Institute of Aerospace Engineering, \\ Langfang 065000, China
}

\author{
Ying Men \\ College of Literature \\ Hebei Univerty, Baoding 071002 , China
}

\begin{abstract}
China Daily is the most influential English newspaper in China. With the deepening of China's opening up, China Daily has become the authoritative medium for foreigners to know more about China and its policies. The corpus material of this study is the news from China Daily related to the NPC, the CPPCC, the 18th National Congress of the CPC and some international news in 2012. The purpose of this study is to give a detailed description of the political news in China Daily. This study analyzes its political nature and stylistic features, such as vocabulary with Chinese characteristics, grammar and syntax.
\end{abstract}

Keywords-component; stylistic features; China Daily ; political news

\section{INTRODUCTION}

China Daily is the first and the most important national English newspaper worldwide, sticking to the main responsibility of helping the world know more about China. It was founded in 1981 when China had just carried out its reform and opening up policy. At present, China Daily is distributed in more than 150 countries and regions around the world. Usually, there are several pages in the newspaper. In China Daily, there are important national news, international news, comments, business news, and entertainment and so on. More importantly, the political news has the largest coverage of the newspaper, thus it is necessary for people to grasp the characteristics of political news in China Daily.

\section{LITERATURE REVIEW}

\section{A. Features of Political News}

Some of scholars studied the particular types of newspolitical news, one category of news. Brown and Yule (1983) pointed out that the analyst has to take account of the context in which the text occurs. In analysis of English political news, context certainly cannot be neglected. Yang Xueyan (2004) found that there are about 38 kinds of stylistic features of news English mentioned by the scholars and experts. But only 12 kinds of them are mentioned by half of the experts. So it is difficult to reach a certain stylistic features by just analyzing typical categories without specified corpus. Thereby, she started the research from the aspect of sub-variety to illustrate the stylistic features of international political news.

What's more, Hu Huatao (2009) stated that political news is the transmission of comments and reports on political truth by a kind of media. It shows the very distinct features of behaviorism. Although political news has the features of authenticity, timeliness and novelty, the most substantial feature of political news is political nature. Political nature means that from reading the report, readers can easily figure out the political stance of the newspaper, so how to show this feature is very important. The journalist always uses political words and pragmatic strategy to reach this goal. Usually political news in China Daily focuses on the leading figures of our government or foreign countries. And the events it reported are always crucial for the global peace or international relations. The configuration of words and grammar in the political news has its certain political intentions. And political language has the features of elaboration, extension and enhancement.

\section{B. Features of China Daily}

Luo Jianguo held (1985) there are many explanations and background information, in order to make foreigners to easily understand the report with Chinese characteristics. It usually uses grammar method, such as appositives, expressions and adverbial clause, to supply background information. In describing some native things, the newspaper will use some words that we are familiar with, however, foreigners can not understand at all. So China Daily chooses to follow some patterns of western newspapers in both layout and writing skills, for the convenience of foreign readers. Most of the pattern of its report follow the Inverted Pyramid Form, that is to put the most excellent and important part — the lead, at the beginning. The following part will be ordered by its importance, important one in the front and sub prime in the back part. What's more, interpretative reporting is a concept different from interpretation in reporting. The news report always chooses interpretative reporting to cooperate with some reports on major events. There are many studies related to news English, but few scholars study on the stylistic features of political news. Studies on the headline, lead, body features of news report are illustrated in the former part. However, studies focused on one specific news paper are much lesser. And this thesis will mainly research into political news in China Daily to give a detailed explanation. By analyzing the political news in China Daily, the study will help readers understand political news more easily.

\section{Features of PolitiCAl NeWS IN CHINA DAILY}

One of the most obvious features of political news is its political nature. Each policy has its particular aim. Reading the political news helps us to know more about our government j) 
and the world's future. Many foreigners are not familiar with other countries. So the news media, as a window of transporting a country's information, plays an important role in establishing the image of a country. However, the standpoint of China Daily is always beautifying our country. That seems not so objective. By analyzing the language of the body parts, the features of political news will be clear.

\section{A. On lexical level}

Lexicology is the study of using of words. Because of the seriousness of news, it will use written English more. Even the direct quotations are mostly spoken English, because the figures in the political news are all important person. The following analysis will be extended from these aspects: words with Chinese characteristic, short words, abbreviated words and inaccuracy.

\section{Words with Chinese characteristics}

The political news in China Daily mostly is concerned with the major events in China and the affairs of Chinese people. It is inevitable that there are quite a number of words with Chinese characteristics. Example:

Bo was former Party chief of Chongqing and a member of the Political Bureau of the CPC Central Committee. (China Daily, Nov08, 2012)

The report is a political manifesto to achieve a new victory for socialism with Chinese characteristics under new circumstances. (China Daily, Nov10, 2012)

The fourth generation of Chinese...have developed the Scientific Outlook on Development, he said. (China Daily, Nov10, 2012)

... of completing the building of a moderately prosperous society in all respects. (China Daily, Nov17, 2012)

The above listed expressions or phrases are all with strong Chinese characteristics. They are born with the development of the nation's situation. As the development of China and its increasing influence in the world, more and more words with Chinese characteristics are accepted and understood by the world.

\section{Short words}

News report is famous for its accuracy and simple, so is the political news. Thus the words should be more accurate to show its seriousness. Example:

It is important to set up a system to rectify any mistakes in time. (China Daily, Nov14, 2012) 2012)

The western world is in a mess now. (China Daily, Nov14,

With a ready smile, appearing relaxed and friendly, $\mathrm{Xi}$ made his first public speech in his new role on Thursday at the Great Hall of the People in Beijing. (China Daily, Nov16, 2012)

These short and simple words do not lessen the degree of the meaning of the sentence but increase its literary grace. It is only writers with excellent language skills that can do this.

\section{Abbreviated word}

As the space is limited, sometimes abbreviated words must be used. It is the words curtailed in some way. When it refers to abbreviation, also called clipping, there are blends, initialisms, clipped words and acronyms. In the body parts, acronyms and clipped words are heavily used. Some organizations worldwide or countrywide will choose to use acronyms, because the fully spelling of the name is too long. EU is the acronym of the European Union; CPPCC is the acronym of the Chinese People's Political Consultative Conference; NPC is the acronym National People's Congress.

\section{Inaccuracy}

Most of the journalists and editors of China Daily are Chinese people. Their logic may be different with the logic of English men. This may results in the inaccuracy of using of words. Sometimes it is difficult for native speakers to understand the language. There are some examples of expressions. They are "mutual cooperation; fully completed; energetically develop". This kind of expressing manner can be accepted by Chinese only, because it is the same as Chinese logic. But in English, if the adjectives have the meaning that is contained in the modified words, there is no need to use the adjectives any more.

\section{B. On grammatical level}

Grammar is the rule to organize sentences. There are many studying aspects on the grammatical level. In this analysis grammatical level includes: tense, appositive, voice.

\section{Tense}

Usually, most of the news reported happened in the past. Then, simple past tense is used in a large number of the reports. However, sometimes simple present tense will be employed to make the readers feel that they are close with the events and the news they have got is the latest one. What's more, present perfect tense is another frequently-used one. Journalists use present perfect tense to illustrate that the consequence of the event is still on now.

\section{Appositive}

Appositive is used to give a further explanation. It is the most typical characteristics of the political news. In the news, the appositive is always heavily used. One of the situations is that the appositive is used to list the title of an important figure. Example:

Cai Mingzhao, spokesman for the 18th National Congress of the Communist Party of China, said on Wednesday China expects the US to... (China Daily, Nov08, 2012)

Another situation is to illustrate the reported news. This is an effective way making the news easily understood. Example:

To date, about 983,000 private companies, including 47,000 foreign-owned companies, have established Party organizations, said Wang Jingqing... (China Daily, Nov08, 2012)

Voice 
When it refers to the voice, it is obvious that there are active voice and passive voice. Generally speaking, the active voice is much more used than the passive voice. Comparing with passive voice, active voice is much shorter and more efficient and apparent in expressing the meaning. Then journalists favor the active voice in news writing. However, in some instances, it needs to emphasize some points which the journalist thinks very important. Then the passive voice will be employed to reach the purpose.

\section{On pragmatic level}

Pragmatics is the study that how the sentence is used to communicate successfully. It can be understood as the analysis of meaning in context.

According to Speech Act Theory, certain quotation has certain meanings, direct or indirect. Direct quotation is clearer for readers to get the information. And it is not easy to be misunderstood. In political news, there are many direct quotations, showing the sagacious and wise verbal of the important person. Sometimes the direct quotation will be the representative words from the common people. This kind of expressing gives readers the chance to understand according to their own experience. Example:

"We believe that Europe will ultimately overcome the debt crisis through their own efforts as well as with help from the international community." said Yi Gang, vice-governor of the People's Bank of China. (China Daily, Mar13, 2012)

In this example above, using direct quotation will have a strong tone and the resolution is increased. Apart from this, direct quotation is an objective way to report. Then more direct quotation will be more enjoyed. But these quotations should be insured about the high news value. Sometimes the speech of the figure is too long to write on the paper. Indirect quotation will be used to sum up the core meaning. This is the efficiency of news language. However, in this way, the original language will be retailed by the journalists. It is inevitable that journalists' attitudes will influence their tone in writing the reports.

\section{Political Nature}

Most traditional political news all have political nature. The political nature means to propagandize the spirit of some organization and the speech made about major events. All in all, these reports are to guarantee the orderly development of the economy, culture, society and education. Not all the political news has apparently political nature. Due to the writing techniques, in some political news the political nature is not obvious. But it is sure that China Daily is the spokesman of our country and party. Thus the political news here must have political nature. Example:

Some Chinese tour operators have halted travel to the Democratic People's Republic of Korea over rising safety concerns, but the cancellations were the travel agents' and tourists' own decisions, the Foreign Ministry said on Wednesday.

Ministry spokesman Hong Lei said the ministry has noticed the cancellations, but "at present, at the China-DPRK border, business is as usual." (April11, 2013)

In this piece of news, Chinese government tries to show its stand on DPRK issues. The cancellation is just the people's action not the government's action. Then everybody can see that China supports DPRK all the time.

\section{Example:}

Foreign Ministry Yun Byung-se said the Republic of Korea had asked China and Russia to intercede with the Democratic People's Republic of Korea to ease tension that has mounted since the UN Security Council imposed new sanctions on Pyongyang after its third nuclear arms test in February. (China Daily, April11, 2013)

China hopes all parties do more to contribute to the peninsula's peace and stability, Hong said.

Washington warned the DPRK on Monday not to undertake another nuclear test or missile launch. (China Daily, April10, 2013)

In these two pieces of news, readers can know that the DPRK enjoys a quite good relationship with Russia and China. And it also reflects tensions between America and DPRK. That is the political nature of political news. Readers can easily judge the political stance of related countries.

\section{CONCLUSION}

The study of political news in China Daily can help readers to get critical information. It is valuable to study the features to know deeply about the political news. This paper chooses the material of three important meetings in o China and some political news internationally. Overall, the purpose of this thesis is to give a detailed description of the political news in China Daily. The material and time of writing the thesis are limited to some degree. There are still a lot of studying perspectives which are not done yet. Much more study on the news in China Daily is needed.

\section{REFERENCES}

[1] Brown, G. \& G. Yule. Discourse Analysis. Cambridge: Cambridge University Press, 1983.

[2] Hou Weirui. English Varieties. Shanghai: Shanghai Foreign Language Education Press, 1988.

[3] Thompson, G. Introducing Functional Grammar. Beijing: Foreign Language Teaching and Research Press, 2000: 32-40.

[4] Hu Huatao, Language Features and Pragmatic Strategies of Political News. News Amateurs, 2009(4)

[5] LuoJianguo, Application of interpretation means in the China Daily reports. Journal of Shanghai Institute of Foreign Languages.1985(1).

[6] Yang Xueyan, Stylistic features of International Political Newes English. Foreign languages studies. 2004(3). 